\title{
Research on Quality and Security Control of Bridge Construction Management
}

\author{
Chunfeng Wu \\ School of Civil Engineering and Architecture, Wuhan University of Technology, Wuhan 430070, \\ China.
}

Keywords: Quality control, Security control, Bridge construction management

\begin{abstract}
With the increasing development of transportation in China, bridges are playing a more and more important role in today's construction. There are many bridge projects in our country, and the quality and safety problems in the construction process are becoming more and more prominent, including bridge crack, bar corrosion, roadbed subsidence and so on. This paper analyzes the causes of quality and safety in bridge construction management, and puts forward the quality and safety control measures to provide some references for the relevant researchers.
\end{abstract}

\section{Introduction}

In the new situation of social and economic development, people's living standard has been greatly improved. The application of all kinds of traffic tools is becoming more and more popular, people show focus on the trend, the general road has been unable to meet the needs of people's daily travel, although the bridge engineering has greatly eased the pressure on the highway, but because of the complexity of the project, the safety and quality management needs to be effective. In transportation, municipal roads and bridges is the key, as the road connecting rivers and low-lying land, the effective protection of the transport hub, has a significant effect on the development of the national economy, providing convenient living conditions for the people, to the surrounding people's life and the image of the city has a larger role, due to the development of municipal road the bridge has been a long time, so the project quality standards are high. In the development of urban construction, various unfavorable factors are usually encountered in the use of municipal roads and bridges, so the quality control of bridge construction is particularly critical. In the process of construction irregularities including construction technology for unqualified material strength, such as lack of view, when the selection of construction materials, if not on the strict implementation of standard material management will lead to the procurement of materials exist the problem of insufficient strength, so that the project has a lower security. In addition, in the construction management, quality management personnel due to many major problems exist and the occupation moral aspects of the lack of effective constraints, it is prone to problems or shoddy work, and these inferior materials once applied to highway bridge engineering is the most direct consequence of reduced durability and safety engineering.

\section{Problems of Quality and Security Control of Bridge Construction Management}

\subsection{Bridge Crack}

In the construction of bridge, the material used is usually concrete. If the proportion of concrete is not reasonably adjusted, there will be cracks in the concrete bridge. The problem of road bridge will bring a direct impact on the actual construction project. Cracks in bridges are common problems in bridge construction, mainly due to the irregular vibration of concrete and the influence of temperature stress. This has a great impact on the normal input and use of the bridge, and may even cause traffic accidents. Various types of bridge cracks in the different possibilities, the possibility of prestressed concrete rigid bridge crack phenomenon is relatively large, but also affected by the concrete material itself makes the cracking degree of difference, and the causes of the cracks are diversity, bridge sequence are the common causes of concrete or other building materials the existence of quality 
problems, the unreasonable construction and maintenance negligence. It also shows that the quality of the municipal bridge and the maintenance of the later road and bridge have a very important role in the quality and safety of the bridge.

\subsection{Bar Corrosion}

In bridge construction, steel is another main construction material. The actual service life of the steel bar has a direct effect on the quality of the whole bridge. But at present, steel corrosion is a common problem in bridge construction in China. The causes of corrosion of steel bars are analyzed. For reasons, the causes of corrosion of steel bars are relatively simple compared with the first two cracks. The causes of reinforcement corrosion are environmental factors, such as acid rain, seawater and vehicle exhaust. Construction factors, such as unreasonable quality control of cement and improper control of water cement ratio, are the main factors for reinforcement corrosion. In the construction of road and bridge, steel bar is especially key. Adding steel bar can improve the hardness of bridge and improve the quality of bridge. However, it is easy to cause corrosion of steel bar in road and bridge. This is due to the lack of steel reinforcement in road and bridge construction, which makes it easier to rust due to oxidation. The corrosion of reinforcing steel is mostly due to various factors such as steel raw materials, environment and even construction. For example, in the course of construction, the concrete, water and other damaged steel bars used by the bridge are not treated in advance. Moreover, if acid rain and other special weather and some other chemicals occur, the corrosion of the steel bar will be affected. The quality of the bridge is improved by the prevention of corrosion through the protection of steel bars.

\subsection{Roadbed Subsidence}

Subgrade subsidence is a common problem in the construction of bridge. The cause is mainly manifested in two aspects: first, the need for municipal bridge approach road of high fill in the construction process, by the rain and snow or load the influence of ground subsidence phenomenon, there are certain risks on pedestrian and traffic; secondly, the bridge construction process of backfill treatment without soil compaction, operating in violation of the requirements of the project, the subgrade and pavement structure subsidence occurs, leading to pavement cracking, normal traffic influence. There is also a certain probability in the south of the day and night. Specifically, the frost cold, temperature changes will have an impact on the subgrade, which leads to the roadbed subsidence. Such subgrade settlement is often controlled by adjusting the construction period, but the duration of the road engineering is quite long. It is not realistic to complete the construction in the gate section when the climate is small. For convenient factors cost factors and construction considerations, the subgrade soil often from the construction area nearby, but the construction area near the soil may not be consistent with the highway roadbed, especially road construction needs these high-quality requirements of subgrade. This subsidence often occurs after the completion of the highway, and has a strong lag.

\section{Countermeasures of Quality and Security Control of Bridge Construction Management}

\subsection{Establish Effective Administrative Mechanisms}

The qualified professional management team and the perfect quality and safety management system and the division of responsibilities are all important guarantees to ensure the quality and safety of the bridge construction. The relevant managers should fully understand the purpose and significance of the work, and carry out the specific responsibilities to the people. Especially to the strict management and technical personnel operating, for emergency treatment measures necessary, strict supervision of the construction process, and to check before construction drawing. For construction and operation personnel, must obtain the corresponding qualification certificate, after the necessary training to posts, the relevant management personnel to conduct safety construction and technical aspects of the disclosure of technical personnel, in the specific work process to strictly abide by the construction plan, etc., for the problems found should be promptly reported to their superiors, 
on relevant issues to effectively solve the problem in a reasonable range. When you meet a sudden safety accident, you should learn to protect yourself. In addition, the construction operators also have the right to obtain construction protection equipment, emergency avoidance and other aspects. The construction process of a project is made up of a series of interrelated and mutually restricted processes, and the quality of the process is the most basic unit of the quality of the project. There are quality defects or hidden dangers in the above process, which not only make the quality of the process less than the standard requirements, but also directly affect the quality and safety of the next process and subsequent projects. Therefore, in the construction to establish a strict shift system in every process must adhere to the self-inspection and mutual inspection, after the completion of the special inspector examination, and then apply for approval to supervision. The supervisors should conscientiously perform their duties and carry out quality inspection strictly according to the current national standards for the quality inspection and evaluation of the building engineering. After inspection, the next process can be carried out.

\subsection{Optimize Design Quality Management}

When designing, the designers should conduct a comprehensive survey of the geographic environment, transportation, pipeline, geology, human flow and other information, and then design the most suitable scheme according to the requirements of the project and the current economic conditions. In the process of design, the designer should discuss the problems in time and put forward the corresponding solutions. The construction technology of bridge construction is the technical support for ensuring the quality of the building, and it can make the quality of the project effectively controlled. During construction, all technologies must be carried out strictly according to construction requirements and standards, and provide more powerful support for bridge engineering by improving the technological level and technology level. In the construction technology, we should make reasonable management for the related personnel in the construction, regularly train and supervise the construction personnel, to minimize the incidence of engineering problems. The design of municipal bridge is also important for the quality of the bridge. Before construction, we need to plan the design according to the environment of the construction site and the water, electricity, gas and heating routes in the construction area. For example, before the subgrade filling, the soil should be tested first, and the test items include the physical properties of water content, maximum dry weight and so on. To ensure that the soil to fill the soil can meet the requirements of the project. In the process of filling, the thickness of each layer should be inspected, and then the compaction will be carried out after the qualification is determined. In the process of subgrade compaction should follow certain principles: from low to high, from light to heavy, then static vibration, pressure on both sides of first press, so that the degree of compaction can meet the engineering standard, reduce the problem of subgrade and pavement subsidence and cracking.

\subsection{Strengthen Material and Equipment Management}

We must check and maintain the re use equipment to ensure the normal and safe operation of the machinery. The equipment should be checked and maintained on time, the equipment should be updated in time, and the conditions of the construction site should be taken into consideration, and the most suitable equipment should be selected. The quality of the construction materials and the quality of the construction equipment will affect the quality of the construction. Therefore, the builders should pay attention to the purchase of the building materials. This requires material purchasers to strictly select materials according to the design requirements of construction projects, and pay attention to quality inspection of materials before entering the field. Avoid the inflow of equipment and materials which are not in conformity with the design requirements or low quality into the actual construction. In addition, the construction personnel should also ensure the quality of materials and equipment at the same time, achieve the cost control as much as possible, and select partners in different prices. Municipal bridge engineering requires a lot of building materials, and these materials directly affect the quality of bridges. Building materials are the first quality control in bridge quality management. Therefore, the quality control of materials is the basis for quality control of bridge 
construction. With the development of the construction industry, building materials market has gained rapid development, increase the building materials building materials market operators to increase the difficulty of management, make the market of mixed fish heads, all kinds of materials, if the material procurement personnel are not professional can be misleading, resulting in the procurement of materials do not meet the standard. Based on this, the professional level of the procurement staff and the choice of suppliers appears particularly important in the purchasing materials. First, we must ensure that the procurement personnel have professional material identification level, and can effectively check the materials, and ensure that the materials purchased can meet the engineering building standards. At the same time, we must compare the suppliers in many aspects and choose the best quality based on the control cost.

\subsection{Improve Inspection and Acceptance Work}

Detailed and strict inspection system is a necessary system in the process of bridge construction. In concrete construction, we must carry out necessary inspections on time, and carry out responsibilities to everyone in every task. To ensure the quality and safety of design, personnel, mechanical equipment, materials and so on through inspection. In addition, a strict quality inspection should be carried out in the completed part. When the construction unit has checked the related projects, it will need to take part in the completion acceptance after the completion of the project. According to the design drawings and specifications, it is necessary for the relevant person in charge to sign the contract. Concrete is the main raw material for the construction of bridge engineering. It is very necessary to strengthen the quality acceptance of concrete during the construction process. Inspection personnel shall be in strict accordance with the supervision of personnel instructions, using non-destructive method for checking the quality of concrete, especially should be on the bridge bored pile and pile quality of each key in-depth investigation, and in the actual construction due to fault and rework perfusion treatment pile integrity test, and ensure the quality of pile. The use of non-destructive method to embedded part of the landfill, it needs to set the basis as the actual construction drawings. To meet the testing requirements, the inspectors should use the equipment that can easily drill core samples in the concrete column, and ensure the technical level of the inspectors. In the construction of large bridge, most of the work of sampling inspection is done by the drilling team with better technical level. When testing personnel in concrete testing, not satisfied with the concrete test, verify whether the quality need to pile below the construction design standards, in this case, the detection personnel shall be at the top of the pile or pile length were detected in core sample extraction, the actual re perfusion on the concrete quality detection.

\section{Conclusion}

The quality of bridge construction is of great significance to the safety of transportation and transportation in China and the development of national economy. The construction quality management is an important content to ensure the quality of the bridge construction. It should run through the whole process of bridge construction. To ensure the safety of construction activities, the safety awareness of the builders must be improved and the management of the site must be strengthened. In this way, the safety of the builders can be ensured effectively, and the construction activities can be carried out smoothly.

\section{References}

[1] Hu Congjian, Pan Jinfeng. Elementary Discussion on Construction Security Control Technology of Highway Bridge [J]. Urban Roads Bridges \& Flood Control, 2013(6): 172-174.

[2] Zhu Xiaopai. Application and Analysis of Safety and Quality Control Measures in Bridge Construction Management [J]. Construction \& Design for Engineering, 2017(12): 165-166.

[3] Zhao Jing. Road and Bridge Construction Technology and Quality Control Measures [J]. 
Construction \& Design for Engineering, 2017(19): 165-167.

[4] Wang Jiqin. Prestressed Technique in Highway Bridge Construction and Construction Quality Control [J]. Value Engineering, 2014(32): 133-134. 